\title{
USAHA PEMBERDAYAAN EKONOMI MASYARAKAT MISKIN YANG MEMILIKI TANGGUNGAN ANAK PENYANDANG CACAT MELALUI KEGIATAN IbM
}

\author{
Eri Yusnita Arvianti' ${ }^{1)}$, Sri Umi Lestari' ${ }^{2)}$, Macaria Theresia Laiyan ${ }^{3)}$ \\ Pascasarjana Universitas Tribhuwana Tunggadewi Malang
}

\begin{abstract}
Fenomena kemiskinan di kalangan masyarakat yang memiliki tanggungan anak cacat merupakan masalah yang perlu segera diatasi. Banyak sekali anak penyandang cacat yang tidak bisa mengenyam bangku pendidikan karena kondisi ekonomi orang tua mereka yang tidak mampu. Kondisi seperti ini timbul karena masyarakat miskin tidak memiliki akses, kemampuan finansial dan ketrampilan yang cukup dalam mengatasi masalah tersebut.

Keluarga penyandang cacat Ridho Eko Atmojo maupun Leni Nurhayati merupakan dua contoh keluarga yang memerlukan bimbingan dan bantuan modal. Rido Eko memiliki kelainan bisu dan tuli, sedangkan Leni memiliki kelainan epilepsy dan retardasi mental ringan. Melalui kegiatan Ipteks bagi masyarakat (IbM) berupa usaha jualan sayur keliling dan beternak ayam kampung ini diharapkan terjadi peningkatan produktivitas dan kemandirian keluarga mitra baik secara ekonomi mapun sosial, juga pemberian rehabilitasi medis si penyandang cacat agar mampu berperan dalam lingkungan sosialnya .

Hasilnya setelah mendapatkan bantuan dari program IbM Keluarga Agus Susanto (Ridho Eko Atmojo) dan Keluarga Setiono (Leni Nurhayati) semakin meningkat produktifitasnya sehingga mampu memperbaiki taraf kehidupan ekonomi dan sosialnya menuju kemandirian ekonomi keluarga. Hasil analisis kelayakan usaha untuk jualan sayur keliling adalah sebesar 1.47 dan usaha beternak ayam sebesar 1.16 sehingga dua kegiatan usaha tersebut layak untuk diusahakan. Pemberian rehab medis memberikan efek positip terhadap tingkat kesehatan kedua anak mitra.
\end{abstract}

Keyword : Miskin, Anak Cacat, Pemberdayaan.

\section{Pendahuluan}

Kemiskinan merupakan suatu hal yang banyak mendapat sorotan dimasyarakat. Gagasan pengembangan masyarakat muncul dalam diskusi keilmuan sebagai sebuah respon terhadap banyaknya masalah yang dihadapi umat manusia pada akhir abad ke 20. Beberapa ahli menyatakan, pengembangan masyarakat merupakan penjelmaan dari sebuat format politik baru pada awal abad ke 20. Pengembangan masyarakat mulai tumbuh sebagai gerakan sosial pada tahun 1970-an menyusul bangkitnya kesadaran progresif dari sebuah komunitas internasional untuk memberikan perhatian model kesejahteraan distri- butif secara radikal, memberlakukan model kewarganegaraan aktif dan memberi ruang bagi partisipasi warga dalam proses pembangunan (Zubaedi, 2007:15).

Keberpihakan terhadap nasib orang-orang yang kurang beruntung dilakukan dengan mengubah model gerakan sosial dari kontrol sosial beralih pada model praktik yang mencoba memberdayakan dan melibatkan mereka dalam proses perencanaan, pelaksanaan program- 
program kemasyarakatan secara kolaboratif- partisipatoris. Dari sini aksi pengembangan masyarakat, perencanaan sosial, dan advokasi sosial untuk kali pertama menjadi model. Praktik social work ini untuk menyempurnakan model kerja kemasyarakatan tradisional yang pernah ada.

Pengembangan masyarakat dalam kontek ini dilaksanakan dengan tujuan pengembangan masyarakat lapisan bawah dalam mengidentifikasikan kebutuhan, mendapatkan sumber daya dalam memenuhi kebutuhan, dan memberdayakan mereka secara bersama-sama. Program pengembangan masyarakat pada hakikatnya menjadi proses aktualisasi komitmen pada aktivitas sosial dalam memecahkan masalah kesenjangan atau ketidakseimbangan antar kelompok masyarakat, ter- masuk mengatasi masalah kelangkaan sumber daya, kesempatan masyarakat untuk menjauhkan dari penderitaan sosial. Setiap pengembangan masyarakat didorong untuk pengembangan sumber daya, ketrampilan, dan peluang untuk hidup secara lebih baik bagi masyarakat kecil. Program pengembangan dilaksanakan para aktivis sosial dengan menggunakan outreach methods (kegiatan keorganisasian yang bersifat melakukan kontrak, serta memberikan pelayanan dan pendampingan kepada anggota masyarakat). Cara ini dilakukan dengan maksud untuk meningkat- kan partisipasi warga dalam berbagai kegiatan masyarakat yang berorientasi untuk memperbaiki kondisi kehidupannya.

Kondisi anak cacat di Indonesia yang memiliki keluarga miskin masih tergolong banyak . Dewasa ini dibuktikan dengan tingginya angka kemiskinan, angka pengangguran, angka putus sekolah, dan meningkatnya jumlah anak kurang gizi. Berdasarkan Badan Pusat Statistik Republik Indonesia pada bulan Maret 2009, tingkat kemiskinan sebesar 14,15 \%, dengan Indeks Kedalaman Kemiskinan sebesar 2,50\% dan Indeks Keparahan Kemiskinan sebesar 0,68 (BPS Hasil Sensus Penduduk 2009). Kondisi ini menunjukkan bahwa warga negara yang mengalami kemiskinan sebesar 14,15\%, hal ini menunjukkan bahwa pem- banguan ekonomi di Indonesia selama ini mengalami distorsi (distorted development). Menurut Midgley (2005) seperti dikutip Zubaedi (2007), pembangunan yang terdistorsi adalah pembanguan ekonomi yang tidak sejalan dengan atau kurang berdampak pada peningkatan kualitas kesejahteraan masyarakat secara luas. Atau dengan perkataan lain pembanguam ekonomi yang mengalami distorsi apabila keuntungan dari pembangunan tidak mampu menyentuh dan meningkatkan taraf kesejahteraan masyarakat secara menyeluruh dan menurunkan jumlah angka kemiskinan secara bermakna.

Program Iptek bagi Masyarakat diharapkan mampu meningkatkan produktifitas dan kemandirian keluarga di bidang sosial dan ekonomi. Hal ini tentunya akan membawa angin segar bagi pengembangan keluarga maupun si anak cacat itu sendiri. Penyandang cacat menjadi tidak terbelakang/minder dalam bergaul dimasyarakat. Sehingga pola pikir dan kemampuan berinteraksi dengan orang lain pun menjadi semakin berkembang.

\section{Metode Pengabdian Masyarakat}

Jenis pengabdian masyarakat yang dilakukan adalah menggunakan metode penyuluhan, pendampingan , aplikasi pembukuan, dan kelayakan usaha. Kegiatan pengabdian dilaksanakan di dua keluarga yang memiliki tanggungan anak penyandang cacat yaitu di keluarga Agus Susanto, di kelurahan Torongrejo dan keluarga Setiono di Kelurahan Landungsari. Alasannya karena dua keluarga tersebut adalah keluarga dengan penghasilan dibawah rata-rata dan termasuk dalam kategori keluarga miskin. Kelurga Agus Susanto diberikan bantuan modal berupa usaha sayur keliling karena sebelunya telah memiliki pengalaman jualan sayur 
keliling namun masih terjerat retenir. Sedangkan keluarga Setiono diberikan bantuan berupa usaha beternak ayam kampung .

Kegiatan Rutin Keluarga Mitra I ( Keluarga Agus Susanto) penjual sayur keliling

- Menyiapkan gerobak dan sepeda motor pukul 02.30 wib pagi

- Bersiap hendak ke pasar pukul 03.00 wib

- Berbelanja kepasar pukul 03.15-06.00 wib (membeli bahan dagangan )

- Persiapan menuju kerumah konsumen pukul 06.15 (ke beberapa perumahan)

- Setelah selesai berdagang sayur keliling, kembali kerumah pukul 09.30

- Memasukkan untung rugi dan pembelian di pembukuan kas

- Menghitung kelayakan usaha jualannya

\section{Kegiatan Mitra II (Keluarga Setiono) Beternak Ayam Kampung}

1. Memberi Pakan

Pemberian pakan untuk jam - jam yang terjadwal.

2. Membuat Catatan Harian

Catatan harian ini meliputi :

- $\quad$ Pemberian pakan dan konsumsi setiap hari,

- $\quad$ Pemberian obat, vitamin dan vaksin,

- $\quad$ Pembelian sarana produksi : pakan, peralatan, dan obat - obatan,

- $\quad$ Produktivitas ayam kematian ayam, penjualan ayam

3. Penimbangan Ayam

Penimbangan anak ayam dilakukan setiap minggu sekali untuk mengetahui laju pertumbuhannya. Penimbangan ayam tersebut tidak dilakukan terhadap semua ayam, tetapi cukup diambil beberapa ekor saja sebagai sample, sekitar $25 \%$ dari setiap kelompok.

Contoh : kelompok anak ayam umur 2 bulan berjumlah 100 ekor, maka yang diambil sebagai sampel 25 ekor saja, kemudian ditimbang. Rata- rata penimbangan sampel, dianggap sebagai rata - rata berat ayam pada umur tersebut.yakit.

Dalam penimbangan, tidak dibedakan antara anak ayam jantan dan betina. Namun ayam dara jantan harus ditimbang sendiri, sebab pertumbuhan ayam jantan pada umumnya lebih cepat daripada ayam betina. Saat berumur 12 minggu ayam jantan sudah mencapai bobot badan 802,05 gram, dan pada umur 28 minggu mencapai 1,8 - 2 kilogram.

4. Menghindarkan Gangguan dari Luar

Gangguan ini dapat berasal dari gangguan binatang lain seperti anjing, kucing, tikus, burung gereja, dan sebagainya. Binatang - binatang ini sering mengganggu, oleh karena itu, orang luar (tamu) yang tidak berkepentingan diusahakan jangan sampai masuk kedalam kompleks peternakan ayam atau tamu yang ingin masuk disuruh membersihkan dulu sandal/ sepatunya dengan obat cuci hama.

5. Membukuan Pembukuan kas

6. Menghitung kelayan usaha beternak ayam kampung pedaging 


\section{A. Hasil dan Pembahasan Masa Pemeliharaan}

a. Masa pemeliharaan pra (starter)

1) Perlakuan awal bibit

Tahapan yang dilakukan yaitu; (1) Masukkan DOC atau anak ayam kedalam kandang brooder guard atau kandang yang diberi pemanas (lampu),(2) Kepadatan didalam kandang harus diatur, sesuaikan dengan umur dan pertumbuhan anak ayam. Aturannya sebagai berikut: DOC umur 1-2 hari 100 ekor/m2, 4 hari - 1 minggu 50 ekor/m2, minggu kedua 25 eekor/m2, minggu ketiga 15 ekor/m2, minggu keempat sampai panen 10 ekor/m2. (3) Selanjutnya diberi minuman vitamin $\mathrm{C}$ dan antibiotic $0,5 \mathrm{ppt}$.

2) Pemberian pakan dan minum

Pemberian pakan dan minum harus diberikan dengan baik. Pakan harus diberikan sesuai porsi yang dibutuhkan, sedangkan minum harus tersedia setiap saat. Yaitu;(1) Minimal 2 jam kemudian (setelah pemberian minum), anak ayam diberikan makan dengan pakan yang telah disediakan, baik pakan komersial seperti broiler crumble (dijual di took makanan ternak) atau dengan mencampur sendiri. Minimal makanan yang diberikan berupa tepung karena DOC belum memiliki alat pencernaan yang sempurna. Pemberian pakan pada hari pertama $4-8$ kali. Pemberian makan pada pagi hari sebaiknya lebih banyak, semakin siang semakin berkurang. (2)Pemberian pakan ditempatkan pada baki pakan. Untuk minum, tempatkan pada baki minum. Posisi tempat pakan dan minum harus mudah dijangkau oleh anak ayam. (3)Pemberian pakan pad hari berikutnya dapat diberikan sebanyak 3 - 7 g per ekor per hari selama 1 minggu. Sebaiknya frekuensi pemberian pakan dilakukan sebanyak 4 kali di pagi hari, siang hari 2 kali, dan sore hari 1 kali. (4)Selanjutnya pakan diberikan sebanyak 10 - 30 g per ekr per hari dengan 3 kali pemberian per hari muai minggu ke-2 hingga ke-5. Pemberian pakan dilakukan dengan meningkatkan porsi secara bertahap, sedangkan pemberian minum dilakukan secara addlibitum (tersedia setiap saat), seperti pada table diatas.

3) Kebutuhan suhu

Tabel 1. Umur anak ayam, Suhu kandang, dan Kepadatan populasi dalam kandang di masa starter

\begin{tabular}{ccc}
\hline Umur (hari) & Suhu Kandang $\left({ }^{\circ} \mathbf{C}\right)$ & Kepadatan $($ ekor/m2) \\
\hline $1-7$ & $32-35$ & $80-100$ \\
$8-14$ & $31-32$ & $60-80$ \\
$15-21$ & $30-31$ & $40-60$ \\
$22-28$ & $29-30$ & $20-40$ \\
$29-35$ & $27-28$ & $10-20$ \\
Ayam dewasa & $27-28$ & $5-10$ \\
\hline
\end{tabular}

4) Penjagaan kesehatan

Pada pemeliharaan di dalam brooder guard atau kandang ayam (kutuk), kondisi anak ayam harus terus dipantau setiap saat. Anak ayam yang tidak memiliki nafsu makan, tidak sehat, lemas, atau tidak banyak bergerak sebaiknya disinkirkan ditempat tersendiri. Begitu pula dengan anak ayam yang pertumbuhannya tergolong lambat, pisahkan dan tangani tersendiri di dalam blok kandang brooder guard khusus(1). Selama masa starter dapat dilakukan vaksinasi, terutama ND-IB untuk tetelo dan gumboro. Vaksinasi untuk pencegahan penyakit ND, infeksi pernapasan, dan gumboro. Disarankan agar dilakukan vaksinasi ND-IB tetes mata sebelum umur 1 minggu, vaksin gumboro sebelum umur 2 minggu(2). Pemberan 
suplemen vitamin dapat dilakukan setiap minggu dengan pengaturan dibeerikan 3 hari berturut-turut, istirahat selama 3 hari, dan lanjutkan 3 hari berikutnya selama pemeliharaan di brooder guard. Dosis suplemen vitamin sesuai dengan aturan yang tertera dalam kemasan komersial, yaitu 0,5\% dari volume air minum yang diberikan(3). Selalu amati kondisi ayam, baik tingkah laku maupun nafsu makannya selama pemeliharaan(4). Lakukan penimbangan anak ayam pada minggu ke-2 dengan mengambil sampel sebanyak 10\% (5).

b. Masa pertumbuhan (grower)

Pada masa grower, ayam membutuhkan pakan yang baik bagi pertumbuhannya. Masa grower ayam kampung berkisar pada pemeliharaan minggu ke-5 hingga ke-8.

1) Pemberian pakan dan minum

Pemberian pakan sebanyak $40-70$ g/ekor per hari selama 4 minggu. Frekuensi pemberian pakan sebaiknya dilakukan sebanyak 3 kali, yaitu pagi, siang, dan sore hari.

Pakan yang diberikan dapat berupa dadak katul 40\%, konsentrat 30\%, dan jagung $30 \%$. Pergantian pakan dari masa starter (broiler crumble) kegrower (pakan campuran) dilakukan secara bertahap, dimulai 3 hari sebelum hari ke-28 sudah dilakukan adaptasi pakan tahap berikutnya. Presentase campuran antara broiler crumble dengan pakan campuran adalah $60 \%$ : 40\% (selama 3 hari, sebelum hari ke-28), 50\%: 50\% (selama 1 hari), 40\% : 60\% (selama 3 hari). Selanjutnya gunakan pakan campuran $100 \%$. Pemberian minum secara addlibitium (tesedia setiap saat) atau seperti pada table di atas untuk umur 5-8 minggu.

2) Kebutuhan suhu

Suhu yang dibutuhkan pada masa grower umur $29-63$ (hari) yaitu $27-28^{\circ} \mathrm{C}$ dengan kepadatan 10 - 20(ekor $\left./ \mathrm{m}^{2}\right)$ keadatannya dapat dilihat pada table di bawah.

3) Penjagaan kesehatan

Vaksinasi pada masa grower berupa ND-IB melalui air minum di minggu kedelapan/kelima (bila perlu). Vaksinasi medivac avian influenza untuk flu burung melalui suntik pada minggu keenam (bila perlu). Pemberian obat cacing pada minggu keenam (bila perlu). Pemberian suplemen vitamin melalui air minum. Lakukan pengamatan kondisi ayam, baik tingkah laku maupun nafsu makan selama pemeliharaan.

c. Masa finisher

Ini merupakan masa akhir untuk segmen sebagai ayam kampung pedaging, yaitu pada umur pemeliharaan9-20 minggu.

1) Pemberian pakan dan minum

Pemberian pakan dan minum sebanyak 70-80 g/ekor per hari pada minggu ke-9 hingga ke-12. Jenis pakan yang diberikan sama dengan masa grower, yaitu pakan campuran. Pemberian pakan 80-100 g/ekor per hari pada minggu ke-12 hingga ke-20. Frekuensi pemberian pakan sebaiknya dilakukan sebanyak 3 kali, yaitu pagi, siang, dan sore hari. minum secara addlibitium untuk umur 9 - 20 minggu.

2) Kebutuhan suhu

Masa finisher yaitu umur anak ayam $64-140$ hari dengan suhu kandang $27-28^{\circ} \mathrm{C}$ dan kepadatan kandang $5-9\left(\mathrm{ekor} / \mathrm{m}^{2}\right)$

3) Penjagaan kesehatan

Vaksinasi tetelo merupakan vaksinasi yang ketiga (bila perlu). Sedangkan itu, vaksinasi yang pertama dilakukan semasa anak ayam, Pemberian obat cacing (bila perlu), Amati kondisi kesehatan ayam, baik tingkah laku maupun nafsu makannya selama pemeliharaan. 
Dari hasil pendampingan beternak ayam di Keluarga Setiono didapatkan data konsumsi pakan dan berat badan mingguan ternak ayam kampung.

Tabel 2. Konsumsi pakan dan berat ayam kampung

\begin{tabular}{ccc}
\hline $\begin{array}{c}\text { Umur } \\
\text { (minggu })\end{array}$ & $\begin{array}{c}\text { Konsumsi pakan } \\
\text { (gr/ekor/mgg) }\end{array}$ & $\begin{array}{c}\text { Berat badan } \\
(\text { gr/ekor })\end{array}$ \\
\hline 1 & 50 & 75 \\
2 & 90 & 110 \\
3 & 160 & 210 \\
4 & 260 & 270 \\
5 & 260 & 350 \\
6 & 290 & 460 \\
7 & 340 & 520 \\
8 & 390 & 580 \\
9 & 440 & 640 \\
10 & 480 & 700 \\
11 & 530 & 760 \\
12 & 590 & 802 \\
\hline
\end{tabular}

Tabel 3. Pemberian Vaksin pada Ayam Kampung

\begin{tabular}{|c|c|c|c|}
\hline $\begin{array}{l}\text { Umur } \\
\text { ayam } \\
\text { (hari) }\end{array}$ & Obat/vaksin & $\begin{array}{c}\text { Cara } \\
\text { pemberian }\end{array}$ & Tujuan \\
\hline 1 & gula pasir dan vita chick & Air minum & $\begin{array}{l}\text { Maningkatkan daya tahan } \\
\text { tubuh, mengatasi stress, } \\
\text { mencegah penyakit } \\
\text { pullorum,kolera, CRD } \\
\text { colibacillosis }\end{array}$ \\
\hline 3 & Vaksin strain $\mathrm{F}$ atau RIVS2 & Tetes mata & $\begin{array}{l}\text { Mencegah ppenyakit ND } \\
\text { Memacu pertumbuhan dan }\end{array}$ \\
\hline $4-6$ & Vita chick atau vita stress & Air minum & $\begin{array}{l}\text { mencegah ayam stress } \\
\text { akibat vaksinasi }\end{array}$ \\
\hline 10 & Vaksin gumboro & $\begin{array}{lr}\text { Tetes } & \text { mulut } \\
\text { atau } & \text { air } \\
\text { minum } & \end{array}$ & $\begin{array}{l}\text { Mencegah } \\
\text { gumboro }\end{array}$ \\
\hline $12-13$ & Vita stres atau fortevit & Air minum & $\begin{array}{l}\text { Mencegah stress akibat } \\
\text { vaksinasi, memacu } \\
\text { pertumbuhan ayam }\end{array}$ \\
\hline 21 & Vaksin strain $\mathrm{F}$ atau RIVS2 & Tetes mata & Mencegah penyakit ND \\
\hline $22-24$ & Vita stress atau fortevit & Air minum & $\begin{array}{l}\text { Mencegah stress akibat } \\
\text { vaksinasi, memacu } \\
\text { pertumbuhan ayam }\end{array}$ \\
\hline 30 & $\begin{array}{l}\text { Vaksin Medicav atau } \\
\text { Avacian influenza }\end{array}$ & Suntik & $\begin{array}{l}\text { Mencegah penyakit flu } \\
\text { burung }\end{array}$ \\
\hline $31-32$ & Vita stress atau fortevit & Air minum & $\begin{array}{lr}\text { Mencegah } & \text { stress akibat } \\
\text { vaksinasi, } & \text { memacu }\end{array}$ \\
\hline
\end{tabular}




\begin{tabular}{|c|c|c|c|}
\hline \\
\hline 42 & Obat cacing & Air minum & $\begin{array}{l}\text { pertumbuhan ayam } \\
\text { Mencegah cacingan }\end{array}$ \\
\hline 60 & Vaksi Strain F atau RIVS2 & Suntik & Mencegah penyakit ND \\
\hline 84 & Obat cacing & Air minum & Mencegah cacingan \\
\hline \multicolumn{4}{|c|}{$\begin{array}{l}\text { b. Analisis Usaha Sayur Keliling (Keluarga Agus Susanto)/Mitra I } \\
\text { Table 4. Investasi }\end{array}$} \\
\hline & Uraian & Unit & Rupiah \\
\hline Sep & Motor & 1 & 4.500 .000 \\
\hline Ger & k sayur & 1 & 250.000 \\
\hline Bel & & 1 & 150.000 \\
\hline Ban & & 1 & 120.000 \\
\hline Tota & ivestasi & & 5.020 .000 \\
\hline \multicolumn{4}{|c|}{ Table 5. Biaya tetap } \\
\hline Ura & & Unit & piah \\
\hline \multicolumn{4}{|c|}{ Biaya penyusutan : } \\
\hline Sep & Motor $1 / 30 x$ 4.500.000 & Buah & 150.000 \\
\hline Ger & k sayur 1/30x 250.000 & Buah & 8.333 \\
\hline Bel & $24 \times 150.000$ & Buah & 6.250 \\
\hline Ban & $/ 24 \times 120.000$ & Buah & 5.000 \\
\hline Tota & iaya tetap & & 169.583 \\
\hline
\end{tabular}

\section{Tabel 6.Biaya tidak tetap}

\begin{tabular}{|c|c|c|}
\hline Uraian & Unit & Rupiah \\
\hline Sayur mayor & $\mathrm{Kg}$ & 2.400 .000 \\
\hline Buah-buahan & $\mathrm{Kg}$ & 645.000 \\
\hline Daging, ikan, ayam & $\mathrm{Kg}$ & 2.400 .000 \\
\hline Bumbu dapur & Gram & 1.200 .000 \\
\hline Bensin 2 liter & 2 liter & 210.000 \\
\hline Total biaya tidak tetap & & 6.855 .000 \\
\hline
\end{tabular}

Bunga Modal $=$ $24 \% / 12 /(169.583+6.855 .000)=140.492$

Biaya total $=(169.583+6.855 .000+140.492)=7.165 .075$

Pendapatan $=10.600 .000$ (omzet)

Keuntungan $=$ Pendapatan - biaya total

$$
=10.600 .000-7.165 .075=3.434 .920
$$

$\mathrm{R} / \mathrm{C}=10.600 .000 / 7.165 .075=1.47$------.> layak diusahakan

Dari hasil perhitungan RC ratio didapatkan bahwa untuk usaha jualan sayur keliling sangat layak untuk diusahakan. Hal ini tergantung pada keuletan mitra dalam menjualkan sayurnya. Manajemen usaha yang baik akan membawa tingkat keuntungan yang tinggi pula.

\section{b. Analisis Usaha Pemeliharaan Ayam (Keluarga Setiono)/Mitra II}

Tabel 7. Investasi

\begin{tabular}{|c|c|c|}
\hline Uraian & Unit & Rupiah \\
\hline Kandang & 4 sisi & 3.000 .000 \\
\hline Pagar keliling & 1 & 500.000 \\
\hline Tempatpakan@5.000 & 4 buah & 20.000 \\
\hline
\end{tabular}




\begin{tabular}{llr}
\hline Tempat minum @ 15.000 & 4 buah & 60.000 \\
Lampu dan pitingan & Buah & 200.000 \\
Seng @ 25.000 & 10 meter & 250.000 \\
Plastik @ 150.000 & 2 lonjor & 300.000 \\
Kabel & 1 rol & 200.000 \\
Total investasi & & $\mathbf{4 . 5 3 0 . 0 0 0}$ \\
\hline Tabel 8. Biaya tetap & Unit & Rupiah \\
\hline Uraian & & \\
\hline Biaya penyusutan : & Buah & \\
Kandang 1/30x3.000.000 & Buah & 100.000 \\
Pagar Keliling 1/30x 500.000 & Buah & 17.000 \\
Tempat pakan 1/24x 20.000 & Buah & 833 \\
Tempat minum 1/24x 60.000 & Buah & 2.500 \\
Lampu dan pitingan 1/24x 200.000 & 8.333 \\
Seng 1/24x 250.000 & Lembar & 10.417 \\
Plastik 1/24x 300.000 & Lonjor & 12.500 \\
Kabel 1/24x 200.000 & Meter & 8.333 \\
\hline Total Biaya tetap & & $\mathbf{1 5 9 . 9 1 0}$ \\
\hline Tabel 9. Biaya tidak tetap & & \\
\hline Uraian & Unit & \\
\hline Pembelian 100 ekor DOC & @ 12.000 & Rupiah \\
Pakan DOC BR 1 comfed & @ 350.000 & \\
Vaksin ND -IB (umur 4 hari) & 1 & $\mathbf{6 . 0 7 0 . 0 0 0}$ \\
Vaksin Gumboro (umur 7 hari) & 1 & 3.500 .000 \\
Vaksin ND Lasota ( 14 hari) & 1 & 50.000 \\
Vaksin Gumboro (25 hari) & 1 & 50.000 \\
Vitamin Neobro 250 gr & 8 bungkus & 60.000 \\
Vitastress 250 gr & 8 bungkus & 60.000 \\
Vitachick 250 gr & 4 bungkus & 200.000 \\
Desinfektan 16 botol & @7500 & 200.000 \\
Formalin 2 liter & @30.000 & 200.000 \\
Kapur & 2 karung & 120.000 \\
Pasir & I piskup & \\
Biaya tali tampar dan paku & & \\
Total biaya tidak tetap & & \\
\hline
\end{tabular}

\section{Bunga Modal $=$}

$24 \% / 12 /(159.910+6.070 .000)=124.598$

Biaya total $=(159.910+6.070 .000+124.598)=6.354 .508$

Pendapatan $=3 / 100$ (tingkat kematian) $\times 100$ ekorx $0.9 \times 85.000=7.420 .500$ (omzet)

Keuntungan $=$ Pendapatan - biaya total

$$
=7.420 .500-6.354 .508=1.065 .992
$$

$\mathbf{R} / \mathbf{C}=7.420 .500 / 6.354 .508=1.16$

Dari hasil perhitungan RC ratio didapatkan bahwa untuk usaha beternak ayam layak diusahakan . Hal ini tergantung pada keuletan mitra dalam memelihara ayam. Manajemen usaha yang baik akan membawa tingkat keuntungan yang tinggi pula. 


\section{c. Rehabilitasi Medis}

Riwayat terapi (Ridho Eko Atmojo, 7 tahun ), mengalami hambatan dalam hal berbicara, ada sedikit tuli.Untuk meningkatkan kemampuan berbicara, Ridho dilatih terapi wicara untuk meningkatkan perbendaraan kata. Untuk mencapai tujuan ini, kami memberikan training kepada orangtua tentang cara melatih berbicara anaknya dengan mendatangkan speechtherapist. Agar Ridho juga diterima di lingkungan sekitar, kami juga meminta kepada orangtua agar mengajak Ridho mengikuti kegiatan di masyarakat.

Padamulanya, keberadaan Ridho sangat sulit diterima di masyarakat. Namun karena juga didukung dengan kegigihan orangtua, pelan-pelan keberadaan Ridho dapat diterima masyarakat setempat. Sekarang Ridho bisa bermain di mana saja dan dengan siapa saja.Untuk memperoleh pendidikan sesuai dengan jenis disabilitasnya, kami merujuk Ridho ke SLB Eka Mandiri Batu, walaupun cukup jauh dari rumahnya. Orang tua pada mulanya perlu dimotivasi agar mau mengantar anaknya ke sekolah. Dan akhirnya Ridho bisa sekolah di SLB Eka Mandiri.

Leni Nurhayati (24 tahun), mengalami epilepsy dan retardasi mental. Lahir kondisi normal, ketika umur 4 hari, jatuh dari gendongan ibunya. Setelah jatuh tidak tampak ada gejala sakit, Leni tumbuh dengan baik seperti anak-anak seusianya.Namun ketika umur 2,5 tahun Leni mulai mengalami kejang seluruh tubuh terus-menerus, tiap 5 menit. Orangtuanya waktu itu tidak memiliki pengetahuan yang cukup sehingga tidak dibawa ke dokter tetapi dibawa ke paranormal, tetapi tidak ada perubahan. Ketika usia 5 tahun Leni masuk sekolahTK, tetapi karena sering kejang, akhirnya keluar dari sekolah TKK. Akibat dari sering kejang, Leni menjadi pemurung, tidak mau ke keluar rumah, apabila keinginannya tidak terpenuhi selalu mengamuk, pergaulan dengan teman juga menjadi terbatas, terjadi kemunduran mental, bicara juga tidak jelas, sungguh keadaannya sangat memprihatinkan. Namun begitu Leni masih bersyukur punya orang tua dan seorang adik yang cukup memberikan perhatian.

Leni mulai rutin dibantu obat epilepsi pada awal tahun 2008, dengan dirujuk ke dokter spesialis syaraf, setelah dilakukan EEG, Leni mendapat obat epilepsy Dilantin 100mg, Vit B6 dan Lapigo 3x1. Perkembangan jenis obat epilepsy yang diminum sekarang adalah Bamgetol XC, Vit B6, Dilantin 50mg XC.Tindakan ini dilakukan secara rutin 1 bulan sekali. Setelah mendapat bantuan obat, pelan-pelan serangannya mulai berkurang. Orangtua selalu mengingatkan Leni untuk minum obat sesuai dengan peraturannya. Leni mengalami serangan jika keinginannya tidak dipenuhi atau pada saat datang bulan.

Disamping itu Leni juga membutuhkan rehabilitasi social. Untuk mengatasi masalah ini, kamipun juga memberikan pelatihan kepada orang tua agar membiasakan untuk mengajak Leni keluar rumah, lalu mengajak jalan-jalan di sekitar rumahnya. Nampaknya usaha ini sungguh berhasil, karena Leni bisa tersenyum, sekali waktu mau membantu orang tua menyapu, memberi makan ayam dan membantu memasak.

\section{Kesimpulan}

Kemadirian Mitra I dan Mitra II dalam berusaha dipengaruhi oleh tingkat semangat kerja dan daya pemikiran untuk mampu merubah hidup kearah lebih baik. Tingakat keuntungan yang semakin meningkat dari tiap bulan dari omset penjualan sebelumnya akan mampu meningkatkan taraf hidup dan kesejahteraan dari kedua Mitra hal ini pula berpengaruh terhadap pola pengasuhan anak cacat dari kedua mitra. Rehabilitasi bagi anak cacat ( Leni dan Eko) harus terus dilakukan pendampingan selain juga suplai pembelian obat secara rutin sehingga si anak dapat tumbuh sehat dan mandiri terhadap lingkungan. 


\section{Ucapan Terima Kasih}

Ucapan terima kasih penulis sampaikan kepada Direktur DP2M Dikti, Direktur Pascasarjana Universitas Tribhuwana Tunggadewi, Ketua LPPM Universitas Tribhuwana Tunggadewi, dan Seluruh tim yang membantu pelaksanakan IbM.

\section{DAFTAR PUSTAKA}

Bungin, Burhan. 2007. Penelitian Kualitatif. (Komunikasi, Ekonomi, Kebijakan Publik, dan Ilmu Sosial lainnya. Jakarta.

Dewanta, Awan Setya (ed.). 1995.Kemiskinan dan Kesenjangan di Indonesia, . Aditya Media.Yogyakarta

Efendi,Muhammad. 2006. Psikopedagogik Anak Berkelainan.Bumi Aksara. Jakarta

Gunarhadi, 2000. Laporan Penelitian Pengembangan Kemampuan Usaha Penyandang Cacat, Surakarta : PPRR UNS

Hidayat, S. 2001. Pemberdayaan Ekonomi Rakyat : sebuah rekonstruksi konsep CBD.PT. Pustaka Quantum.Jakarta

Kholid, Anwar. 2012. Kunci Sukses Beternak dan Bisnis Ayam Kampung. Araska. Yogyakarta

Krista, B dan Harianto, B. 2010.Beternak dan Bisnis Ayam Kampung. Agromedia Pustaka. Jakarta

Salim, Abdul , 1996. Evaluasi dan Pengembangan Sistem Rehabilitasi Penyandang cacat di PRSBD Prof. Dr. Soeharso Surakarta “, PPRR UNS, 2000.

Suryana, Dr. Msi, Kewirausahaan (2003) Salemba Empat, Jakarta Suwarto, Saparinto C.2012. Usaha Ayam Kampung Pedaging secara Intensif. Andi Ofset.Yogyakarta

Soeparman Soemahamidjaja. (1997). Membina Sikap Mental Wirausaha. Gunung Jati. Jakarta

Suparjan dan Suyatno Hempri. 2003. Pengembangan Masyarakat dari Pem-bangunan Sampai Pemberdayaan. Aditya Media. Yogyakarta.

Zubaedi. 2007. Wacana Pembangunan Alternatif. (Ragam Persektif Pengem-bangan dan pemberdayaan Masyarakat). Yogyakarta. Ar-Ruzz Media Group. 